\title{
Temperature Influence on Potato Leaf and Branch Distribution and on Canopy Photosynthetic Rate
}

\author{
David H. Fleisher,* Dennis J. Timlin, and Vangimalla R. Reddy
}

\begin{abstract}
Mature potato (Solanum tuberosum L. cv. Kennebec) canopies are composed of leaves originating from main- and axillary-stem branches. Canopy leaf distribution and its corresponding contribution to wholecanopy photosynthetic rates have not been quantified. An experiment using SPAR (Soil-Plant-Atmosphere-Research) chambers maintained at 16-h day/night thermoperiods of 14/10, 17/12, 20/15, 23/18, $28 / 23$, and $34 / 29^{\circ} \mathrm{C}$ was conducted. Mature canopies were divided into three horizontal layers of equal depth. Canopies were defoliated at each layer, from the ground upward, on successive days. Response curves for photosynthetic rate vs. irradiance were obtained after each defoliation. Leaf area within each layer followed a quadratic relationship with temperature. The largest areas were between 16.6 and $22.1^{\circ} \mathrm{C}$. Main-stem leaves accounted for $>50 \%$ of the total leaf area at temperatures $<22^{\circ} \mathrm{C}$, while the proportion of axillary-stem leaf area in each layer increased with temperature. Canopy maximum gross photosynthetic rates, $A_{\mathrm{MAX}}$, before harvest ranged from 9.5 to $34.8 \mu \mathrm{mol}$ $\mathrm{CO}_{2} \mathrm{~m}^{-2} \mathrm{~s}^{-1}$ (production-area basis) and were higher at 14/10, 17/12, and $20 / 15^{\circ} \mathrm{C}$ temperatures than at $23 / 18,28 / 23$, and $34 / 29^{\circ} \mathrm{C}$. These values were largely related to the quantity of leaf area in each chamber. The value of $A_{\mathrm{MAX}}$ and canopy light use efficiency declined as successive canopy layers were removed, primarily due to decreases in canopy light interception. These results indicate that the relative proportion of main- or axillary-stem leaves are not as important for potato canopy modeling considerations as is the need to simulate the correct quantity of leaf area.
\end{abstract}

$\mathrm{T}$ EMPERATURE profoundly influences the growth and development of the potato canopy. Leaf appearance, expansion, and senescence (Kirk and Marshall, 1992; van Delden et al., 2001; Vos, 1995), leaf orientation and physiological age (Ng and Loomis, 1984; Steward et al., 1981), and stem elongation and branching (Allen and Scott, 1980; Marinus and Bodlaender, 1975; Struik et al., 1989) are significantly correlated with temperature. The leaf-level photosynthetic rate also varies with temperature; however, few whole-canopy gas exchange studies have been conducted (Hammes and De Jager, 1990; Ku et al., 1977; Prange et al., 1990; Thornton et al., 1996).

Most potato models (e.g., SUBSTOR and LINTULPOTATO) represent the canopy as a single large stem and homogenous leaf layer (e.g., IBSNAT, 1993; Kooman and Haverkort, 1995; Shaykewich et al., 1998). Increases in canopy leaf area are simulated as an exponential or

\footnotetext{
USDA-ARS Crop Systems and Global Change Lab., 10300 Baltimore Ave., Beltsville, MD 20705. Mention of a trademark or proprietary product does not constitute a guarantee or warranty of the product by the USDA and does not imply the exclusion of other available products. Received 1 Dec. 2006. *Corresponding author (dfleishe@ asrr.arsusda.gov)
}

Published in Agron. J. 98:1442-1452 (2006).

Potato

doi:10.2134/agronj2005.0322

(C) American Society of Agronomy

677 S. Segoe Rd., Madison, WI 53711 USA nonlinear function of temperature. Canopy leaf area is used to estimate the interception of PAR (photosynthetically active radiation). Increases in plant mass (grams per plant) are computed by multiplying light interception by a constant value for radiation use efficiency (grams of biomass per megajoule of intercepted PAR; e.g., IBSNAT, 1993; Kooman and Haverkort, 1995; Shaykewich et al., 1998). Potato models can be improved by including more detailed canopy responses to temperature (Vos, 1995). More sophisticated modeling approaches that estimate canopy photosynthetic rate by integrating gas exchange from different leaf layers in the canopy have been developed to improve accuracy in other crop models (e.g., Boote and Pickering, 1994). Knowledge of potato leaf and branch distribution at different canopy depths and their contribution to plant growth rate is needed to adopt these approaches for potato.

Potato is an indeterminate crop with regard to its growth habit (Allen and Scott, 1980; Ewing, 1997; Vos, 1995); vegetative growth can continue well after floral and tuber initiation. Potato main stems terminate in an inflorescence, at which point typically two apical, or upper, axillary stems develop from the axils of the second and third leaf below the inflorescence. Basal axillary stems can also emerge between the axils of lower leaves on the main stem. Basal and apical axillary stems also terminate in an inflorescence and may give rise to additional lateral branches, depending on cultivar, planting density, plant assimilate supply, soil nutrition, and environmental conditions (Steward et al., 1981; Vos, 1995; Vos and Biemond, 1992). Thus, mature potato canopies are composed of leaves and branches that can be classified as main, basal, or apical (e.g., main-stem branch and main-stem leaves, basal-stem branch and basal-stem leaves, apical-stem branch and apical-stem leaves).

The manner in which potato branches and leaves are distributed throughout the canopy and their corresponding contribution to photosynthetic rate has not been quantified. Air temperatures at $23^{\circ} \mathrm{C}$ and above increase the number of axillary branches and the leaf appearance and senescence rates (Manrique et al., 1989; Marinus and Bodlaender, 1975). Cooler temperatures promote lower total leaf and branch numbers, but produce larger leaves that remain photosynthetically active for longer periods of time (Benoit et al., 1986; Manrique et al., 1989; Marinus and Bodlaender, 1975; Wolf et al., 1990). Growth temperatures $>25^{\circ} \mathrm{C}$ produce plants with elongated stems, smaller leaves, increased internode number, and inhibited tuber development (Borah and Milthorpe, 1962; Steward et al., 1981; Struik et al., 1989). Optimum tem-

Abbreviations: IPAR, intercepted photosynthetically active radiation; PAR, photosynthetically active radiation; PPF, photosynthetic photon flux; SPAR, Soil-Plant-Atmosphere-Research. 
peratures for leaf-level photosynthetic rate range from 20 to $24^{\circ} \mathrm{C}$ (Hammes and De Jager, 1990; Ku et al., 1977; Prange et al., 1990; Thornton et al., 1996). Warmer temperatures reduce the net photosynthetic rate; however, it is difficult to extrapolate leaf-level measurements to the whole canopy (Thornton et al., 1996). Differences in canopy composition according to basal, apical, and main-stem branches and leaves would be expected at different growth temperatures and these differences may influence wholecanopy gas exchange.

In this study, the influence of air temperature on lateral stem and leaf production at different layers in the potato canopy was investigated. The leaf area of different canopy layers and its distribution according to main, basal, or apical stem was evaluated as a function of air temperature. Measurements of whole-plant gross photosynthetic response vs. irradiance following sequential harvesting of canopy layers were used to further assess the contribution of these layers to whole-plant gas exchange rates. This information can be used to address knowledge gaps in existing potato crop models.

\section{MATERIALS AND METHODS Plant Culture}

Certified potato (cv. Kennebec) seed tubers $(54.9 \pm 10.04 \mathrm{~g}$ mean fresh weight) were planted in a 50:50 peat/vermiculite potting medium in $15-\mathrm{L}$ pots at a depth of $5 \mathrm{~cm}$ in the summer of 2004 at the USDA-ARS facilities in Beltsville, MD. Pots were kept in reach-in growth chambers (Environmental Growth Chambers, Chagrin Falls, $\mathrm{OH}$ ) at $20^{\circ} \mathrm{C}$ with a 16 -h photoperiod and 6.61 MJ PAR m ${ }^{-2} \mathrm{~d}^{-1}\left(550 \mu \mathrm{mol} \mathrm{m}^{-2} \mathrm{~s}^{-1}\right.$ PPF [photosynthetic photon flux density]) until 5 DAE (days after emergence). Plants were selected for uniformity based on leaf count, thinned to a single main stem per pot, and transferred to one of six outdoor SPAR (Soil-Plant-Atmosphere-Research) chambers $\left(12\right.$ plants $\left.\mathrm{m}^{-2}\right)$. The SPAR chambers were set to one of six different day/night temperature regimes: 14/10, 17/12, 20/ $15,23 / 18,28 / 23$, and $34 / 29^{\circ} \mathrm{C}$ with a 16 -h day/night thermoperiod. Average 24-h air temperatures (and standard deviations) for the duration of the experiment were $12.7 \pm 1.92$, $15.9 \pm 3.13,19.3 \pm 2.30,22.0 \pm 2.27,26.7 \pm 2.29$, and $32.1 \pm$ $2.34^{\circ} \mathrm{C}$ for each chamber, respectively. Average, maximum, and minimum photosynthetic irradiance was $7.9 \pm 2.59,12.0$, and 1.6 MJ PAR m ${ }^{-2} \mathrm{~d}^{-1}$ for all treatments, typical values for this region of the USA. The photoperiod during the experiment was approximately $14 \mathrm{~h}$. A minimum of $370 \mu \mathrm{mol} \mathrm{mol}^{-1}$ atmospheric $\left[\mathrm{CO}_{2}\right]$ was maintained at all times during the day. Nighttime $\left[\mathrm{CO}_{2}\right]$ was uncontrolled and ranged between 500 and $733 \mu \mathrm{mol} \mathrm{mol}^{-1}$. Plants were irrigated once per day with tap water ( $2 \mathrm{~L}$ per pot). Each pot received $500 \mathrm{~mL}$ of nutrient solution (Robinson, 1984) twice per week before $30 \mathrm{DAE}$ and $1000 \mathrm{~mL}$ after 30 DAE.

\section{SPAR Chambers}

The SPAR chambers used in this research were described in detail by Reddy et al. (2001). The chambers were rectangular, with a horizontal production area of $1 \mathrm{~m}^{2}$, a height of $2.3 \mathrm{~m}$, and a total growing volume of $3360 \mathrm{~L}$. Chamber walls and ceiling were transparent to sunlight. Fiberglass shading material (Reddy et al., 2001), adjusted for plant height twice per week, was applied to the sidewalls to eliminate the need for border plants. Air temperature was controlled and water vapor removed by solenoid valves that injected chilled water through cooling coils located in the air handler of each chamber. A dedicated Sun SPARC 5 work station (Sun Microsystems, Mountainview, CA) logged environmental data (air and soil-media temperatures, relative humidity, $\left[\mathrm{CO}_{2}\right]$, and PAR above and below the canopy) every 300 s. Ambient PAR was measured with a quantum sensor (LI-190 SA, LI-COR, Lincoln, NE) maintained at $5 \mathrm{~cm}$ above the top of the canopy in each chamber. Quantum line sensors (LI-191 SA, LI-COR, Lincoln, NE), one per chamber, measured PAR at the bottom of the canopy.

Each chamber formed a semiclosed system for measurement of $\left[\mathrm{CO}_{2}\right]$ flux. The $\mathrm{CO}_{2}$ leakage rates were estimated daily for each chamber using an $\mathrm{N}_{2} \mathrm{O}$ tracer gas system (Baker et al., 2004). Each chamber was fitted with its own infrared gas analyzer (Model no. LI-6262, LI-COR Biosciences, Lincoln, NE) and pure $\mathrm{CO}_{2}$ supplied from a compressed gas cylinder to mass flow controllers (Omega Engineering, Stanford, CT) located in the air ducting in each chamber using a feed-forward, feedback PID (proportional integral derivative) control algorithm was used to maintain $\left[\mathrm{CO}_{2}\right]$. The amount of $\mathrm{CO}_{2}$ injected, the amount leaking from the system, and the amount injected but not taken up by the plants were all used to calculate the CER $\left(\mathrm{CO}_{2}\right.$ exchange rate, $\left.\mu \mathrm{mol} \mathrm{CO} \mathrm{CO}_{2}^{-2} \mathrm{~s}^{-1}\right)$ at 5-min intervals.

During the daytime, CER values represent net photosynthesis, $A_{\mathrm{N}}$. Two mean values for dark respiration, $R_{\mathrm{D}}$, at day and night temperatures, were estimated each 24 -h period. Daytime $R_{\mathrm{D}}$ was obtained by averaging CER values at the day temperature between 20:00 and 22:00 when PAR was zero, and nighttime, or dark period, $R_{\mathrm{D}}$ was estimated at the night temperature between 01:00 and 04:00. Resulting $R_{\mathrm{D}}$ values were added to $A_{\mathrm{N}}$ to estimate gross photosynthesis (Eq. [1]). Although $R_{\mathrm{D}}$ does not account for photorespiration and may be affected by $\mathrm{CO}_{2}$, this method has successfully been used to relate C assimilation to dry matter (Dutton et al., 1988; Reddy et al., 1989; van Iersel and Kang, 2002) from growth chamber data.

$$
A_{\mathrm{G}}=A_{\mathrm{N}}+R_{\mathrm{D}}
$$

where $A_{\mathrm{G}}$ is gross instantaneous photosynthetic rate $(\mu \mathrm{mol} \mathrm{CO}$ $\left.\mathrm{m}^{-2} \mathrm{~s}^{-1}\right), A_{\mathrm{N}}$ is net instantaneous photosynthetic rate $\left(\mu \mathrm{mol} \mathrm{CO} \mathrm{CO}_{2}\right.$ $\left.\mathrm{m}^{-2} \mathrm{~s}^{-1}\right)$, and $R_{\mathrm{D}}$ is dark respiration $\left(\mu \mathrm{mol} \mathrm{CO} \mathrm{Cm}^{-2} \mathrm{~s}^{-1}\right)$.

\section{Harvest Procedures}

Each chamber was harvested during a 3-d period. Initial harvest dates were determined based on the time at which expansion of the uppermost main-stem leaf ceased (Table 1). Plant canopies were divided into three horizontal layers (B, bottom; M, middle; T, top; Fig. 1) based on the height of the main stem plus the longest apical-stem branches (Table 1). The high standard deviations at the $20 / 15$ and $34 / 29^{\circ} \mathrm{C}$ treatments (Table 1) was due to the lack of apical branch development on two to three plants in those chambers. Leaves were harvested from each layer in the morning on successive days, starting with Layer B on Day 1, M on Day 2, and T on Day 3, and immediately measured using a leaf area meter (Model no. LI-

Table 1. Starting harvest date $H$ (DAE, days after emergence) and total plant height and standard deviation at harvest for each temperature treatment.

\begin{tabular}{lccr}
\hline Treatment & $H$ & Height & SD \\
\hline day/night $^{\circ} \mathrm{C}$ & DAE & & cm \\
\cline { 3 - 4 } $14 / 10$ & 64 & 22.8 & $\mathbf{3 . 0 4}$ \\
$17 / 12$ & 63 & 27.4 & $\mathbf{3 . 8 0}$ \\
$20 / 15$ & 63 & 31.3 & $\mathbf{4 . 3 9}$ \\
$23 / 18$ & 57 & 67.3 & $\mathbf{7 . 7 0}$ \\
$28 / 23$ & 55 & 48.0 & $\mathbf{1 4 . 4 5}$ \\
$34 / 29$ & 50 & & \\
\hline
\end{tabular}


Top
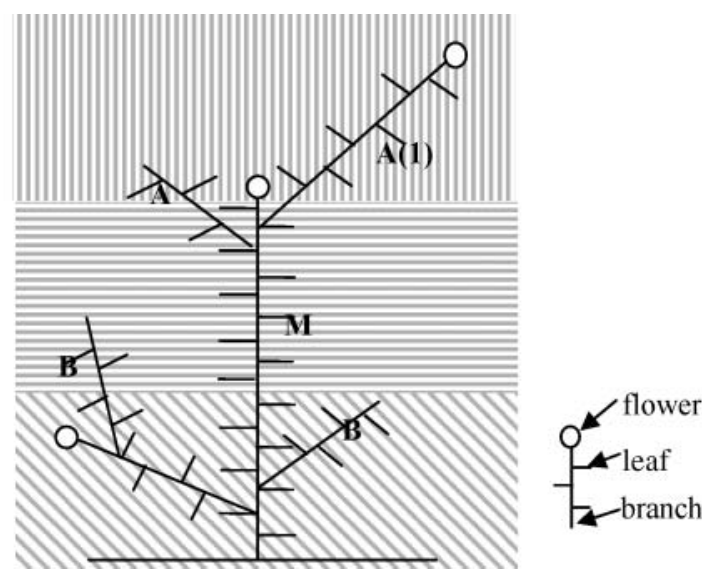

Fig. 1. Schematic representation of a hypothetical potato plant shown with main (M), basal (B), and apical (A) stems. For harvesting purposes, the canopy was divided into three horizontal sections (top, middle, and bottom), each $1 / 3$ the height of the main stem plus the longest apical-stem [A(1)] branches.

3100, LI-COR Biosciences, Lincoln, NE). The branch from which the leaf originated (main, basal, or apical stem) was recorded. A minimum of $9 \mathrm{~h}$ of daylight was available following each harvest so that response curves of photosynthetic rate vs. irradiance (ranging between 0 and $1800 \mu \mathrm{mol} \mathrm{PPF} \mathrm{m}^{-2} \mathrm{~s}^{-1}$ ) could be measured for the remaining canopy layers. The quantum line sensor was moved upward to rest $\sim 5 \mathrm{~cm}$ below the bottom of the remaining leaf canopy. Intercepted photosynthetically active radiation, IPAR, was computed as the ratio between incident and below-canopy measured PAR values. Changes in IPAR due to successive canopy harvesting were recorded and the percentage reduction in IPAR between the full canopy and harvested canopy, \% IPAR, was computed as:

$$
\% \operatorname{IPAR}(i)=100 \frac{[\operatorname{IPAR}(\text { full })-\operatorname{IPAR}(i)]}{\operatorname{IPAR}(\text { full })}
$$

where \% IPAR $(i)$ is percentage reduction of IPAR due to the harvested canopy layer, IPAR $(i)$ is IPAR measured following canopy harvest of the bottom $(i=\mathrm{M}+\mathrm{T})$ or middle layer $(i=\mathrm{T})$, and IPAR(full) is IPAR measured with all canopy layers before harvest of the bottom layer.

After final harvest of Layer T, all branches were harvested and separated according to main, basal, or apical stem types. All leaves, stems, roots, and tubers were dried at $70^{\circ} \mathrm{C}$ until constant weight. Senesced leaves were collected periodically from each chamber and included in the analysis of total biomass at harvest.

\section{Data Analysis}

Canopy gas exchange data were averaged at 15 -min intervals for the full canopy $(\mathrm{B}+\mathrm{M}+\mathrm{T})$ before harvest (Day 0 ) and the remaining canopy at harvest Day $1(\mathrm{M}+\mathrm{T})$ and $2(\mathrm{~T})$. A rectangular hyperbola (Eq. [3]; Loomis and Connor, 1996) was fit to the relationship between $A_{\mathrm{G}}$ (hereafter referred to as measured $A_{\mathrm{G}}$ ) and irradiance for each day of interest (note that $1 \mathrm{~J} \mathrm{PAR}=4.57 \mu \mathrm{mol}$ PPF as in Thimijan and Heins, 1983):

$$
A_{\mathrm{G}}=\frac{\alpha I A_{\mathrm{MAX}}}{\alpha I+A_{\mathrm{MAX}}}
$$

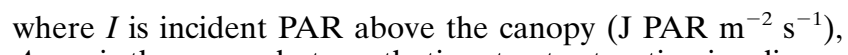
$A_{\mathrm{MAX}}$ is the gross photosynthetic rate at saturating irradiance
( $\mu \mathrm{mol} \mathrm{CO} \mathrm{CO}^{-2} \mathrm{~s}^{-1}$ ), and $\alpha$ is canopy light use efficiency ( $\mu \mathrm{mol}$ $\mathrm{CO}_{2} \mathrm{~J}^{-1}$ PAR).

The NLIN procedure in SAS (SAS Institute, 2001) was used to obtain parameter values using the Gauss-Newton nonlinear least squares iterative method.

Regression was used to analyze the temperature response on harvest components at final harvest (total, leaf, stem, and tuber dry mass and leaf area) and leaf area from harvests of each canopy layer. The SAS procedure Proc Mixed (Littell et al., 1996) was used to calculate the coefficients of the regression. The experiment was analyzed as a repeated measures design with temperature as a fixed effect, chambers as subjects, and harvest canopy layer as the repeated measurement. Temperature, expressed as the average of the observed 24-h temperature measured in each chamber during the experiment, was the continuous variable applied to the chambers. The covariance was modeled as an autoregressive response. The Proc Mixed procedure was also used for analysis of final harvest components, with chamber as the random variable. There were 12 replications of harvested plants for each subplot (harvest period). Regression lines were fitted to the response of each dry matter variable to temperature and the regression coefficients tested for significance. Because Proc Mixed uses a maximum likelihood method to perform the regression analysis, sums of squares are not computed (Littell et al., 1996) and a direct $r^{2}$ value cannot be obtained. Instead, the slope between predicted and observed values is provided, with a value closest to 1 indicating the best possible fit. Tables are provided that show the regression coefficient and standard errors (only significant coefficients $[P<0.05]$ were included in a particular model). Estimates were used to compare coefficients among the regression equations for final harvest components and for leaf area at different canopy layers and at different temperatures. Common coefficients are used to indicate no significant difference.

\section{RESULTS \\ Final Harvest Components}

Means and regression coefficients of final harvest components vs. temperature are summarized in Tables 2 and 3. Linear and quadratic terms were sufficient to describe the relationship between harvest components and temperature. Total biomass increased with cooler temperatures (maximum at $16.6^{\circ} \mathrm{C}$ ) primarily due to tuber dry mass (Fig. 2A). Total leaf dry mass and leaf area showed a similar trend (Fig. 2B and 2D). Main-stem leaf area represented the largest fraction of canopy leaf area at temperatures $<24^{\circ} \mathrm{C}$ (Fig. 2D and 2F). As temperatures increased, canopy branch mass increased (maximum at $23^{\circ} \mathrm{C}$ ) while leaf dry mass decreased (Fig. 2B). This response is primarily due to increased basal- and apical-stem branch growth (Fig. 2C and 2E), more rapid senescence of main-stem leaf area, and smaller leaf sizes at warmer temperatures. At an average temperature of $32^{\circ} \mathrm{C}$ (corresponding to the $34 / 29^{\circ} \mathrm{C}$ treatment), no tubers initiated (Fig. 2A). Root dry mass was not correlated with temperature (Table 2).

\section{Sequential Harvest Components}

Treatment means and regression coefficients for total and main-, basal-, and apical-stem leaf area within each 
Table 2. Means and standard deviations for final harvest components per temperature treatment (day/night $\left.{ }^{\circ} \mathrm{C}\right)$ expressed on a per plant basis.

\begin{tabular}{|c|c|c|c|c|c|c|c|c|c|c|c|c|}
\hline \multirow[b]{2}{*}{ Component } & \multicolumn{2}{|c|}{$14 / 10^{\circ} \mathrm{C}$} & \multicolumn{2}{|c|}{$17 / 12^{\circ} \mathrm{C}$} & \multicolumn{2}{|c|}{$20 / 15^{\circ} \mathrm{C}$} & \multicolumn{2}{|c|}{$23 / 18^{\circ} \mathrm{C}$} & \multicolumn{2}{|c|}{$28 / 23^{\circ} \mathrm{C}$} & \multicolumn{2}{|c|}{$34 / 29^{\circ} \mathrm{C}$} \\
\hline & Mean & SD & Mean & SD & Mean & SD & Mean & SD & Mean & SD & Mean & SD \\
\hline \multicolumn{13}{|c|}{ Dry mass, $\mathrm{g}$ plant $^{-1}$} \\
\hline Total & 93 & 18.0 & 103 & 19.5 & 103 & 20.6 & 87 & 20.2 & 64 & 17 & 13 & 6.9 \\
\hline Tubers & 75 & 15.8 & 80 & 17.9 & 79 & 17.9 & 55 & 16.4 & 24 & 9.5 & 0 & 0 \\
\hline Roots & 4 & 1.4 & 4 & 18 & 4 & 18 & 5 & 2.1 & 4 & 1 & 1 & 0.8 \\
\hline Dead leaves & 0 & 0.4 & 1 & 0.4 & 3 & 1.9 & 5 & 4.5 & 5 & 2.9 & 5 & 2.8 \\
\hline Leaves & 12 & 2.7 & 15 & 3.8 & 13 & 3.7 & 12 & 5.1 & 17 & 5 & 3 & 2.8 \\
\hline Branchs & 2 & 1.2 & 3 & 1.4 & 5 & 3.2 & 10 & 5.6 & 13 & 4.9 & 4 & 3.8 \\
\hline Main stems & 2 & 1.0 & 2 & 0.6 & 3 & 1.2 & 5 & 1.9 & 4 & 0.6 & 1 & 0.9 \\
\hline Basal stems & 0 & 0.2 & 1 & 0.8 & 1 & 1.1 & 3 & 1.6 & 7 & 3.4 & 3 & 2.4 \\
\hline Apical stems & 0 & 0 & 0 & 0.1 & 0 & 1.0 & 2 & 2.1 & 2 & 0.9 & 1 & 0.5 \\
\hline \multicolumn{13}{|c|}{ Leaf area, $\mathrm{cm}^{2}$ plant ${ }^{-1}$} \\
\hline Total & 2580 & 506 & 3292 & 443 & 3152 & 867 & 2292 & 724 & 2254 & 399 & 365 & 381 \\
\hline Main stems & 2211 & 290 & 2706 & 353 & 2310 & 598 & 1086 & 481 & 478 & 178 & 29 & 43 \\
\hline Basal stems & 369 & 250 & 500 & 355 & 703 & 375 & 736 & 330 & 1170 & 586 & 248 & 274 \\
\hline Apical stems & 0 & o & 89 & 96 & 139 & 73 & 468 & 196 & 606 & 211 & 88 & 95 \\
\hline
\end{tabular}

canopy layer vs. temperature were obtained (Tables 4 and 5). Most regressions included a significant positive linear term and a small negative quadratic term. This result indicates that, within a given layer of the canopy, leaf area contributed from a particular branch type increased until an optimum temperature value was reached, at which point it gradually decreased (Table 5, Fig. 3); however, the different coefficients indicated in Table 5 show that the exact responses for leaf area vs. temperature vary with branch type and with canopy layer as explained below.

Common linear and quadratic slopes were obtained for the regressions of the total stem leaf area within each canopy layer ("Total" in Table 5) vs. temperature; however, a different intercept was obtained for B than $\mathrm{M}$ or $\mathrm{T}$ layers. This result indicates that the response of total leaf area in each layer of the canopy with temperature was identical, but with an offset of about $-300 \mathrm{~cm}^{2}$ in the B layer (Fig. 3A). Main-stem leaf area for B and $M$ layers had common slopes and intercepts, while the $\mathrm{T}$ layer had a large negative slope, indicating a more rapid decline with increasing temperature for the $\mathrm{T}$ layer (Fig. 3B). Basal- and apical-stem leaf area had different linear or quadratic terms, indicating that the exact temperature response for leaf area for these branch types also varied by canopy layer (Fig. 3C and 3D). Basalstem leaf area showed a similar response to increasing temperature in all layers. No apical-stem leaf area was measured in the B layer; however, apical-stem leaf area in the $\mathrm{T}$ canopy layer showed stronger responses to increasing temperature than the M layer (Fig. 3D). For both of these branch types, the majority of leaf area was in the T canopy layer (Fig. 3C and 3D).

Figure 4 shows the fraction of total leaf area within each canopy layer attributed to main-, basal-, or apicalstem leaf area. Main-stem leaves accounted for most

Table 3. Regression coefficients (and standard errors) for final harvest components vs. average 24-h temperature corresponding to each temperature treatment.

\begin{tabular}{|c|c|c|c|c|c|c|c|}
\hline Component & Intercept & SE & Linear & SE & Quadratic & SE & Slope \\
\hline & \multicolumn{2}{|c|}{$-\mathrm{g}$ or $\mathrm{cm}^{2}$ plant ${ }^{-1}$} & \multicolumn{2}{|c|}{$\begin{array}{c}-\mathbf{g} \text { or } \mathbf{c m}^{2} \text { plant } \\
\underline{\text { Dry mass }}\end{array}$} & \multicolumn{2}{|c|}{- g or $\mathrm{cm}^{2}$ plant ${ }^{-1}{ }^{\circ} \mathrm{C}^{-2}-$} & \\
\hline Total & - & - & 12.23 & 0.38 & -0.37 & 0.015 & 0.997 \\
\hline Tubers & - & - & 9.63 & 0.36 & -0.31 & 0.014 & 0.982 \\
\hline Dead leaf & - & - & - & - & 0.01 & 0.001 & 0.908 \\
\hline Branch & -31.2 & 5.42 & 3.31 & 0.512 & -0.07 & 0.013 & 0.893 \\
\hline Main stem & -11.02 & 1.83 & 1.34 & 0.173 & -0.03 & 0.0038 & 0.965 \\
\hline Basal stem & -13.1 & 3.55 & 1.27 & 0.335 & -0.02 & 0.0074 & 0.811 \\
\hline Apical stem & - & - & 0.043 & 0.028 & -0.0001 & 0.0011 & $\mathbf{0 . 5 7 2}$ \\
\hline \multicolumn{8}{|c|}{$\underline{\text { Leaf area }}$} \\
\hline Total & - & - & 362.75 & 13.99 & -10.86 & 0.54 & 0.99 \\
\hline Main stem & - & - & 284.02 & 13.06 & -9.25 & $\mathbf{0 . 5 0 3}$ & 0.932 \\
\hline Basal stem & - & - & 63.49 & 10.02 & -1.45 & 0.39 & 0.853 \\
\hline Apical stem & 1942.3 & 277.05 & 196.5 & 26.19 & -4.07 & 0.58 & 0.83 \\
\hline \multicolumn{8}{|c|}{ Fraction of total branch dry mass or leaf area } \\
\hline \multicolumn{8}{|l|}{ Branch } \\
\hline Main stem & 1.31 & 0.0063 & -0.035 & 0.0029 & - & - & 1.01 \\
\hline Basal stem & - & - & - & - & 0.0009 & 0.00004 & 0.978 \\
\hline Apical stem & - & - & - & - & 0.0003 & 0.00003 & 0.862 \\
\hline \multicolumn{8}{|l|}{ Leaf area } \\
\hline Main stem & 1.54 & 0.052 & -0.047 & 0.0023 & - & - & 0.994 \\
\hline Basal stem & - & - & - & - & 0.0007 & 0.00003 & 1.02 \\
\hline Apical stem & -0.59 & 0.184 & 0.055 & 0.002 & -0.0009 & 0.00004 & $\mathbf{0 . 9 3 5}$ \\
\hline
\end{tabular}

$\dagger$ The slope of a regression line fit to predicted vs. observed data. 

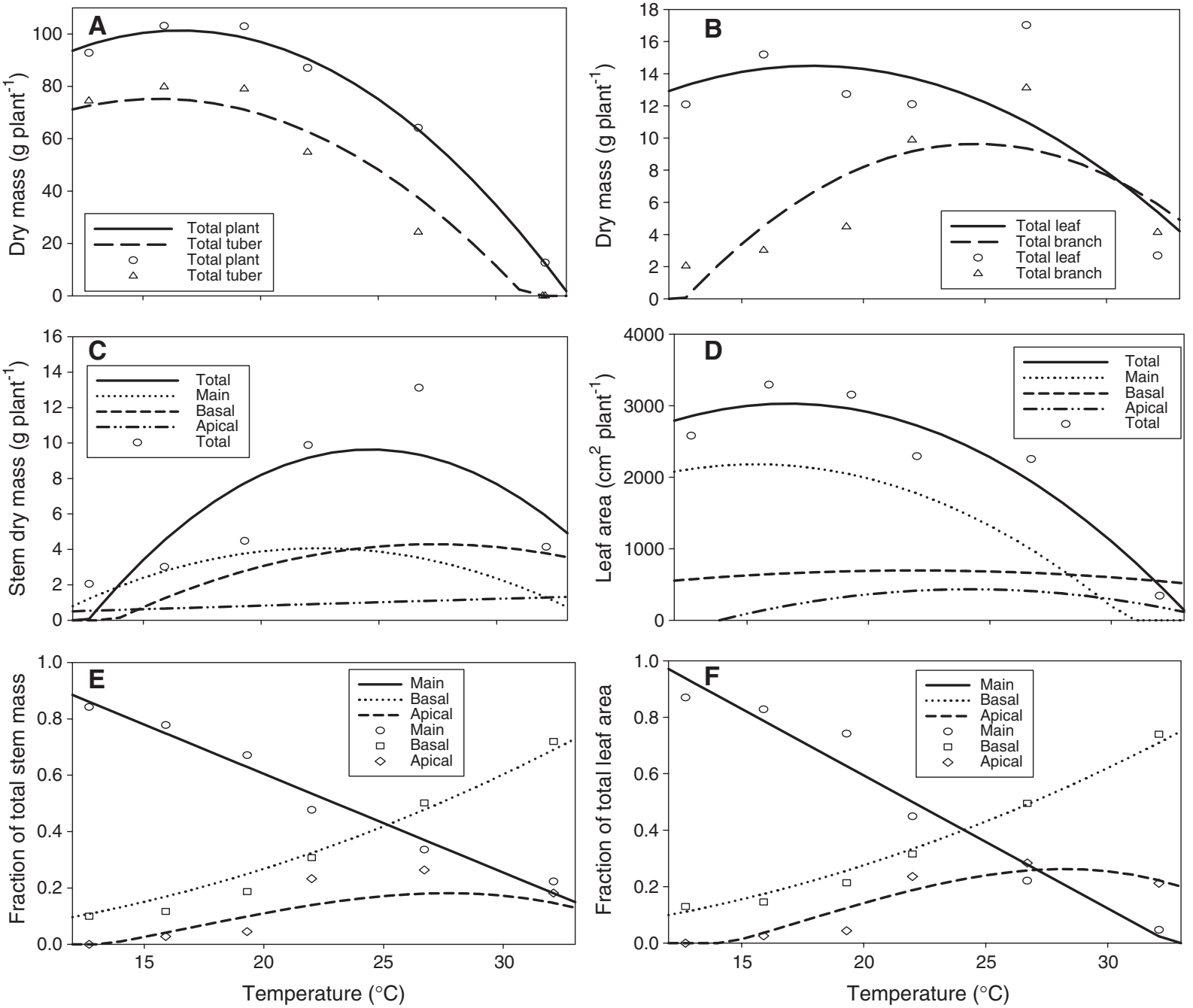

Fig. 2. Pooled harvest components vs. average 24-h temperature ( $\left.{ }^{\circ} \mathrm{C}\right)$ : (A) total and tuber dry mass; (B) branch and leaf dry mass; (C) total and main-, basal-, and apical-stem branch dry mass; (D) total and main-, basal-, and apical-stem leaf area; and fraction of total branch (E) dry mass or (F) leaf area from main-, basal-, and apical-stem branches or leaves. Symbols are observed data, lines are trend lines estimated with the coefficients in Table 3; observed data for branch and leaf components not shown to improve clarity.

of the leaf area in the bottom and middle layers of the canopy until basal- and apical-stem leaf area increased at $\sim 27^{\circ} \mathrm{C}$ and higher (Fig. 4A and $4 \mathrm{~B}$ ). Basal-stem leaf area accounted for $>50 \%$ once temperatures exceeded $27^{\circ} \mathrm{C}$. In the top layer, basal- and apical-stem leaves contributed most of the leaf area by $22^{\circ} \mathrm{C}$ and above (Fig. 4C). As temperatures increased, basal-stem leaf area was twice that of apical.

Table 4. Means and standard deviations for leaf area of each branch type (all stems pooled together [total], main stem, basal stem, or apical stem) at different potato canopy layers (B, bottom; $M$, middle; and T, top layer) for each temperature treatment (day/night).

\begin{tabular}{|c|c|c|c|c|c|c|c|c|c|c|c|c|c|}
\hline \multirow[b]{3}{*}{ Branch type } & \multirow[b]{3}{*}{ Layer } & \multicolumn{12}{|c|}{ Leaf area } \\
\hline & & \multicolumn{2}{|c|}{$14 / 10^{\circ} \mathrm{C}$} & \multicolumn{2}{|c|}{$17 / 12^{\circ} \mathrm{C}$} & \multicolumn{2}{|c|}{$20 / 15^{\circ} \mathrm{C}$} & \multicolumn{2}{|c|}{$23 / 18^{\circ} \mathrm{C}$} & \multicolumn{2}{|c|}{$28 / 23^{\circ} \mathrm{C}$} & \multicolumn{2}{|c|}{$34 / 29^{\circ} \mathrm{C}$} \\
\hline & & Mean & SD & Mean & SD & Mean & SD & Mean & SD & Mean & SD & Mean & SD \\
\hline & & & & & & & $-\mathrm{cm}^{2}$ & $\mathrm{nt}^{-1}$ & & & & & \\
\hline \multirow[t]{3}{*}{ Total } & B & 540 & 243.3 & 986 & 169.8 & 875 & 519.6 & 563 & 329.9 & 434 & 196.5 & 48 & 60.4 \\
\hline & $\mathbf{M}$ & 1097 & 252 & 1290 & 285.7 & 1044 & 281.8 & 761 & 236.9 & 845 & 223.1 & 87 & 107.5 \\
\hline & $\mathbf{T}$ & 942 & 283.9 & 1016 & 336.8 & 1233 & 385.6 & 968 & 300.2 & 974 & 320.6 & 229 & 243.9 \\
\hline \multirow[t]{3}{*}{ Main stem } & B & 398 & 182.8 & 819 & 235.2 & 693 & 460.2 & 497 & 301.9 & 212 & 153.7 & 9 & 18.7 \\
\hline & $\mathbf{M}$ & 969 & 171.8 & 1137 & 229.3 & 894 & 180.4 & 511 & 212.3 & 249 & 89.3 & 16 & 29.7 \\
\hline & $\mathbf{T}$ & 845 & 261 & 749 & 274.6 & 724 & 180.8 & 79 & 111.7 & 17 & 44.4 & 3 & 11.7 \\
\hline \multirow{3}{*}{ Basal stem } & B & 142 & 91.8 & 167 & 138.4 & 183 & 116.4 & 66 & 42.3 & 222 & 119.7 & 39 & 53.4 \\
\hline & $\mathbf{M}$ & 129 & 103.6 & 153 & 109.4 & 150 & 136.7 & 207 & 109 & 413 & 201.9 & 59 & 71.3 \\
\hline & $\mathbf{T}$ & 97 & 88.8 & 179 & 154.6 & 371 & 249.6 & 463 & 225.4 & 535 & 339.7 & 150 & 163.8 \\
\hline \multirow[t]{3}{*}{ Apical stem } & B & 0 & 0 & 0 & 0 & 0 & 0 & 0 & 0 & 0 & 0 & 0 & O \\
\hline & $\mathbf{M}$ & 0 & 0 & 0 & 0 & O & 0 & 43 & 75.7 & 183 & 142.8 & 13 & 20.8 \\
\hline & $\mathbf{T}$ & 0 & 0 & 88 & 95.9 & 138 & 72.5 & 425 & 161.9 & 423 & 168.4 & 75 & 87.1 \\
\hline
\end{tabular}


Table 5. Regression coefficients and standard errors for leaf area vs. 24-h daily air temperature. Separate regressions were fit to each branch type (all stems pooled together [total], main stem, basal stem, or apical stem) at each potato canopy layer (B, bottom; M, middle; T, top).

\begin{tabular}{|c|c|c|c|c|c|c|c|c|}
\hline Branch type & Layer & Intercept & SE & Linear & SE & Quadratic & SE & Slope $\dagger$ \\
\hline & & $\mathbf{c m}$ & & $-\mathrm{cm}^{2} p$ & ${ }^{\circ} \mathbf{C}^{-1}-$ & $-\mathrm{cm}^{2}$ pla & -2 & \\
\hline \multirow[t]{2}{*}{ Total } & B & -505.6 & 320.0 & 148.3 & 30.24 & -4.2 & 0.67 & 0.969 \\
\hline & $\mathbf{M}, \mathbf{T} \downarrow$ & $-\mathbf{1 9 7 . 3}$ & 319.0 & 148.3 & 30.24 & -4.2 & 0.67 & 0.975 \\
\hline \multirow[t]{2}{*}{ Main stem } & $\mathbf{B}, \mathbf{M} \doteqdot$ & 520.4 & 381.82 & 50.8 & 30.2 & -2.2 & 0.67 & 0.973 \\
\hline & $\mathbf{T}$ & 2259.6 & 404.82 & -125.7 & 38.3 & 1.7 & 0.85 & 0.917 \\
\hline \multirow[t]{3}{*}{ Basal stem } & B & -789.3 & 212.65 & 93.4 & 20 & -2.1 & 0.45 & 1.04 \\
\hline & $\mathbf{M}$ & -804.1 & 212.68 & 93.4 & 20 & -2.0 & 0.45 & 0.847 \\
\hline & $\mathbf{T}$ & -742.1 & 213 & 93.4 & 20 & -1.9 & 0.45 & 0.884 \\
\hline \multirow[t]{3}{*}{ Apical stem } & B & NS & NS & NS & NS & NS & NS & - \\
\hline & $\mathbf{M}$ & -351.6 & 144.98 & 33.2 & 13.78 & -0.6 & 0.31 & 0.507 \\
\hline & $\mathbf{T}$ & -1567.3 & 143.48 & 160.7 & 13.58 & -3.4 & 0.30 & 0.88 \\
\hline \multirow[t]{3}{*}{ Main-stem fraction } & B & 0.11 & 0.364 & 0.085 & 0.0346 & -0.003 & 0.001 & 0.926 \\
\hline & $\mathbf{M}$ & 0.96 & 0.361 & 0.015 & 0.0344 & -0.0013 & 0.001 & 0.989 \\
\hline & $\mathbf{T}$ & 2.66 & 0.360 & -0.166 & 0.0341 & 0.0026 & 0.001 & 0.956 \\
\hline \multirow[t]{3}{*}{ Basal-stem fraction } & B & 0.91 & 0.284 & $-\mathbf{0 . 0 8 8}$ & 0.027 & 0.003 & 0.001 & 1.104 \\
\hline & $\mathbf{M}$ & 0.17 & 0.282 & $-\mathbf{0 . 0 2 3}$ & 0.027 & 0.001 & 0.001 & 0.974 \\
\hline & $\mathbf{T}$ & -0.25 & 0.282 & 0.024 & 0.001 & 0.0002 & 0.001 & 0.989 \\
\hline \multirow{2}{*}{ Apical-stem fraction } & $\mathbf{B}$ & NS & NS & NS & NS & NS & NS & - \\
\hline & $\mathbf{M}, \mathbf{T} \ddagger$ & -0.9 & 0.249 & 0.079 & 0.024 & -0.0014 & 0.001 & 0.96 \\
\hline
\end{tabular}

$\dagger$ The slope of the regression line fit to predicted vs. observed data.

$\uparrow$ Regression coefficients were not significantly different for these canopy layers.

\section{Photosynthetic Performance at Different Canopy Depths}

Nonlinear regression results for Eq. [3] are summarized in Table 6. Predicted and measured $A_{\mathrm{G}}$ vs. irradiance at successive harvests is illustrated in Fig. 5. The initial slope of the curve at the origin is $\alpha$, canopy light use efficiency, and the asymptotic value of $A_{\mathrm{G}}$ when light is no longer limiting is $A_{\mathrm{MAX}}$. The parameters $\alpha$ and $A_{\mathrm{MAX}}$ declined as successive canopy layers were removed within a given treatment when expressed on a production-area basis (Table 6). The top canopy layer accounted for 60 to $80 \%$ of the total PAR intercepted by the full canopy (\%IPAR, Table 6) indicating that the decrease in parameter values was probably due to changes in light interception. No clear patterns in $R_{\mathrm{D}}$ were
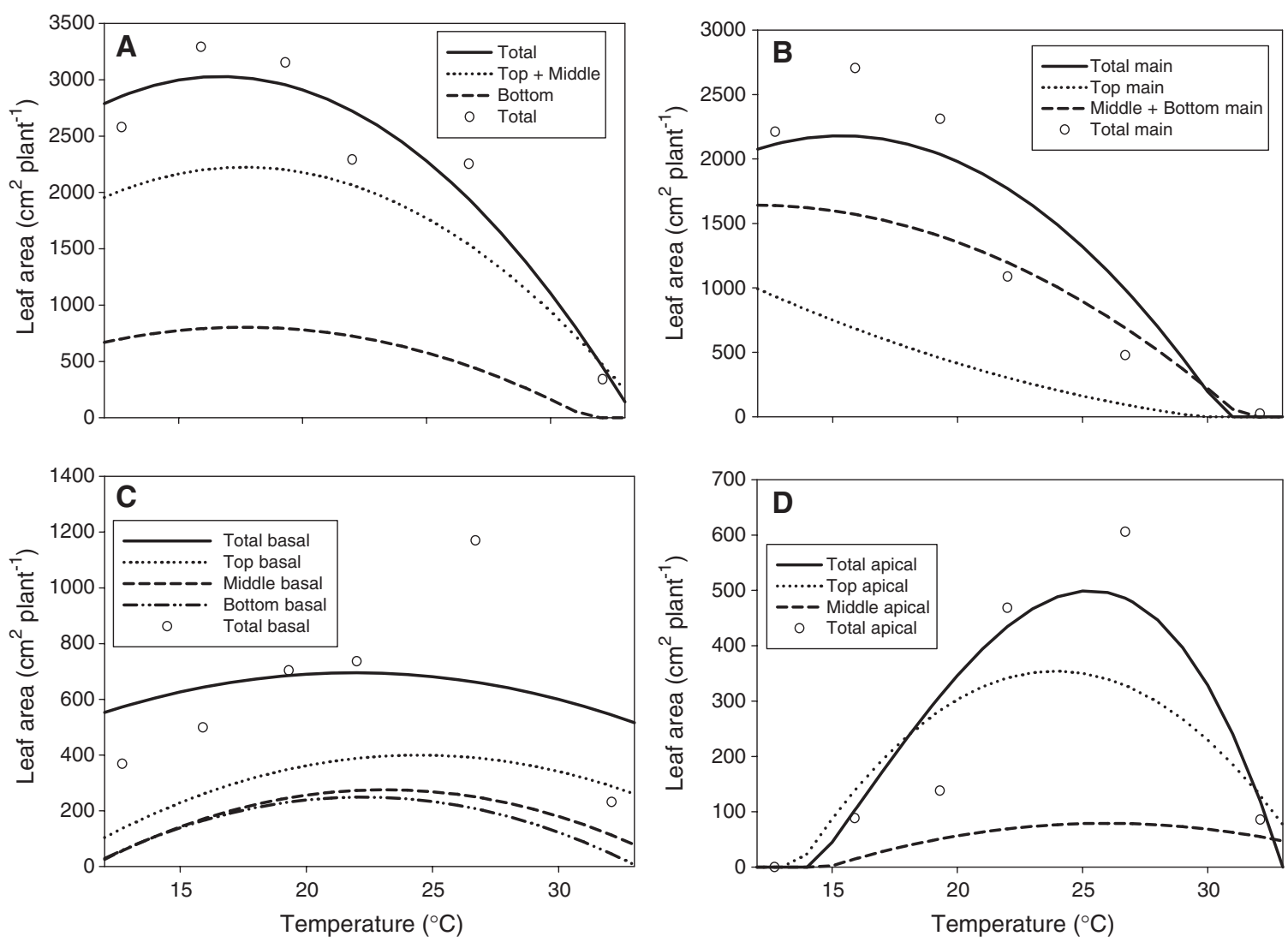

Fig. 3. Leaf area vs. observed average 24-h temperature at different canopy layers: (A) total leaf area; (B) main-stem leaf area; (C) basal-stem leaf area; and (D) apical-stem leaf area. Symbols are observed data, lines are trend lines estimated with regression coefficients in Table 5; observed data from individual canopy layers not shown to improve clarity. Common regression coefficients were obtained for the top and middle layers in (A) and the bottom and middle layers in (B). 

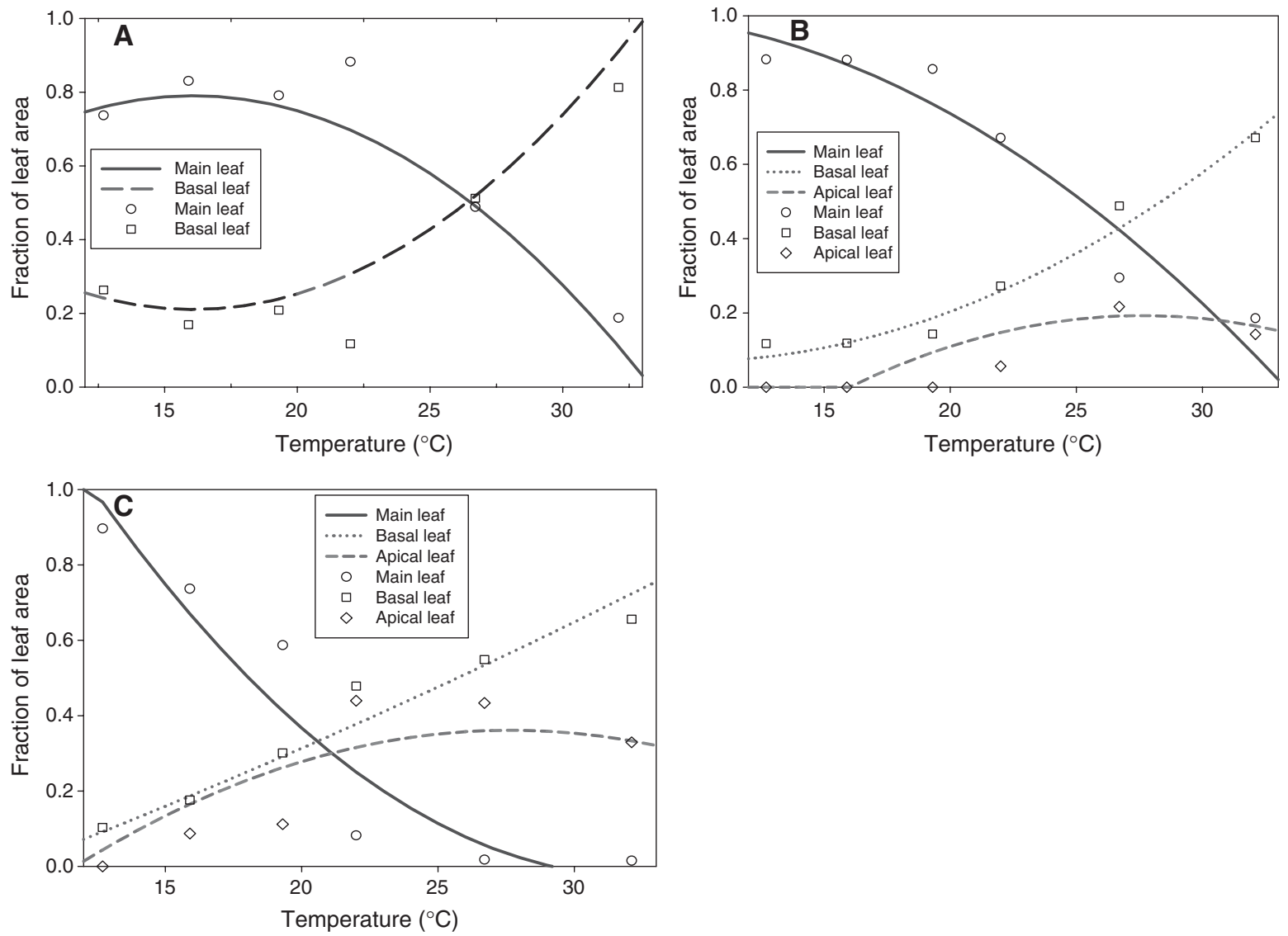

Fig. 4. Fraction of leaf area per canopy layer attributed to stem type vs. observed average 24-h temperature: (A) bottom layer; (B) middle layer; and (C) top layer. Symbols are observed data, lines are trend lines estimated with the regression coefficients in Table 5.

observed as successive layers were removed (Table 6). Within a given temperature treatment, the $\mathrm{M}$ and $\mathrm{T}$ canopy layers were responsible for $>75 \%$ of $A_{\mathrm{MAX}}$, with the uppermost canopy layer accounting for $50 \%$ or more in most of the treatments.

\section{DISCUSSION}

Although plants were harvested at different chronological times, their physiological ages were similar. Harvest times for each treatment (Table 1) started when main-stem leaf expansion ceased. These times coincided

Table 6. Reduction of intercepted photosynthetically active radiation (IPAR) after removal of leaves from lower canopy layer, canopy maximum light use efficiency $(\alpha)$ and standard error, maximum rate at saturating irradiance $\left(A_{M A x}\right)$ and standard error, mean square error, and dark respiration $\left(R_{\mathrm{D}}\right)$ for the remaining canopy layers by temperature treatment (day/night).

\begin{tabular}{|c|c|c|c|c|c|c|c|c|}
\hline Treatment & $\begin{array}{c}\text { Canopy } \\
\text { layer } \dagger\end{array}$ & IPAR & $\alpha$ & SE & $A_{\mathbf{M A X}}$ & SE & MSE & $R_{\mathbf{D}}$ \\
\hline & & $\%$ & $-\mu \mathrm{mol}$ & PAR - & $-\mu \mathrm{mol}$ & $s^{-1}-$ & $10^{-3}\left(\mu \mathrm{mol} \mathrm{CO}_{2} \mathrm{~m}^{-2} \mathrm{~s}^{-1}\right)^{2}$ & $\mu \mathrm{mol} \mathrm{CO} 2 \mathrm{~m}^{-2} \mathrm{~s}^{-1}$ \\
\hline \multirow{3}{*}{$14 / 10^{\circ} \mathrm{C}$} & full & 0 & 0.52 & 0.02 & 29.8 & 1.09 & 2.221 & 3.41 \\
\hline & $\mathbf{M}+\mathbf{T}$ & 8.6 & 0.22 & 0.01 & 27.1 & 0.52 & 0.274 & 3.18 \\
\hline & $\mathbf{T}$ & 23.7 & 0.12 & 0.01 & 15.0 & 0.66 & 0.356 & 2.73 \\
\hline \multirow{3}{*}{$17 / 12^{\circ} \mathrm{C}$} & full & 0 & 0.37 & 0.02 & 34.8 & 0.98 & 2.577 & 2.95 \\
\hline & $\mathbf{M}+\mathbf{T}$ & 14.6 & 0.16 & 0.01 & 26.4 & 0.64 & 0.263 & 1.14 \\
\hline & $\mathbf{T}$ & 41.7 & 0.15 & 0.01 & 14.8 & 0.32 & 0.139 & 1.14 \\
\hline \multirow{3}{*}{$20 / 15^{\circ} \mathrm{C}$} & full & 0 & 0.25 & 0.01 & 31.1 & 0.80 & 1.111 & 3.18 \\
\hline & $\mathbf{M}+\mathbf{T}$ & 7.5 & 0.20 & 0.01 & 19.1 & 0.36 & 0.645 & 3.41 \\
\hline & $\mathbf{T}$ & 29.0 & 0.16 & 0.01 & 12.1 & 0.32 & 0.253 & 2.73 \\
\hline \multirow{3}{*}{$23 / 18^{\circ} \mathrm{C}$} & full & 0 & 0.17 & 0.01 & 26.3 & 0.93 & 1.157 & 2.95 \\
\hline & $\mathbf{M}+\mathbf{T}$ & 12.0 & 0.19 & 0.01 & 17.3 & 0.50 & 0.362 & 4.55 \\
\hline & $\mathbf{T}$ & 38.0 & 0.09 & 0.01 & 15.9 & 0.68 & 0.248 & 2.95 \\
\hline \multirow[t]{3}{*}{$28 / 23^{\circ} \mathrm{C}$} & full & 0 & 0.19 & 0.01 & 26.3 & 0.75 & 0.739 & 6.34 \\
\hline & $\mathbf{M}+\mathbf{T}$ & $\ddagger$ & 0.16 & 0.01 & 20.0 & 0.77 & 0.336 & 6.11 \\
\hline & $\mathbf{T}$ & 29.3 & 0.00 & 0.01 & 10.9 & 0.34 & 0.191 & 5.70 \\
\hline \multirow[t]{3}{*}{$34 / 29^{\circ} \mathrm{C}$} & full & 0 & 0.09 & 0.01 & 9.53 & 0.41 & 0.341 & 5.43 \\
\hline & $\mathbf{M}+\mathbf{T}$ & 6.6 & 0.09 & 0.02 & 6.36 & 0.89 & 0.527 & 6.30 \\
\hline & $\mathbf{T}$ & 19.7 & 0.09 & 0.01 & 5.68 & 2.02 & 0.150 & 7.27 \\
\hline
\end{tabular}

$\dagger$ Full, full canopy; M+T, canopy with bottom layer removed; T, canopy with bottom and middle layers removed.

Data not recorded on this date. 

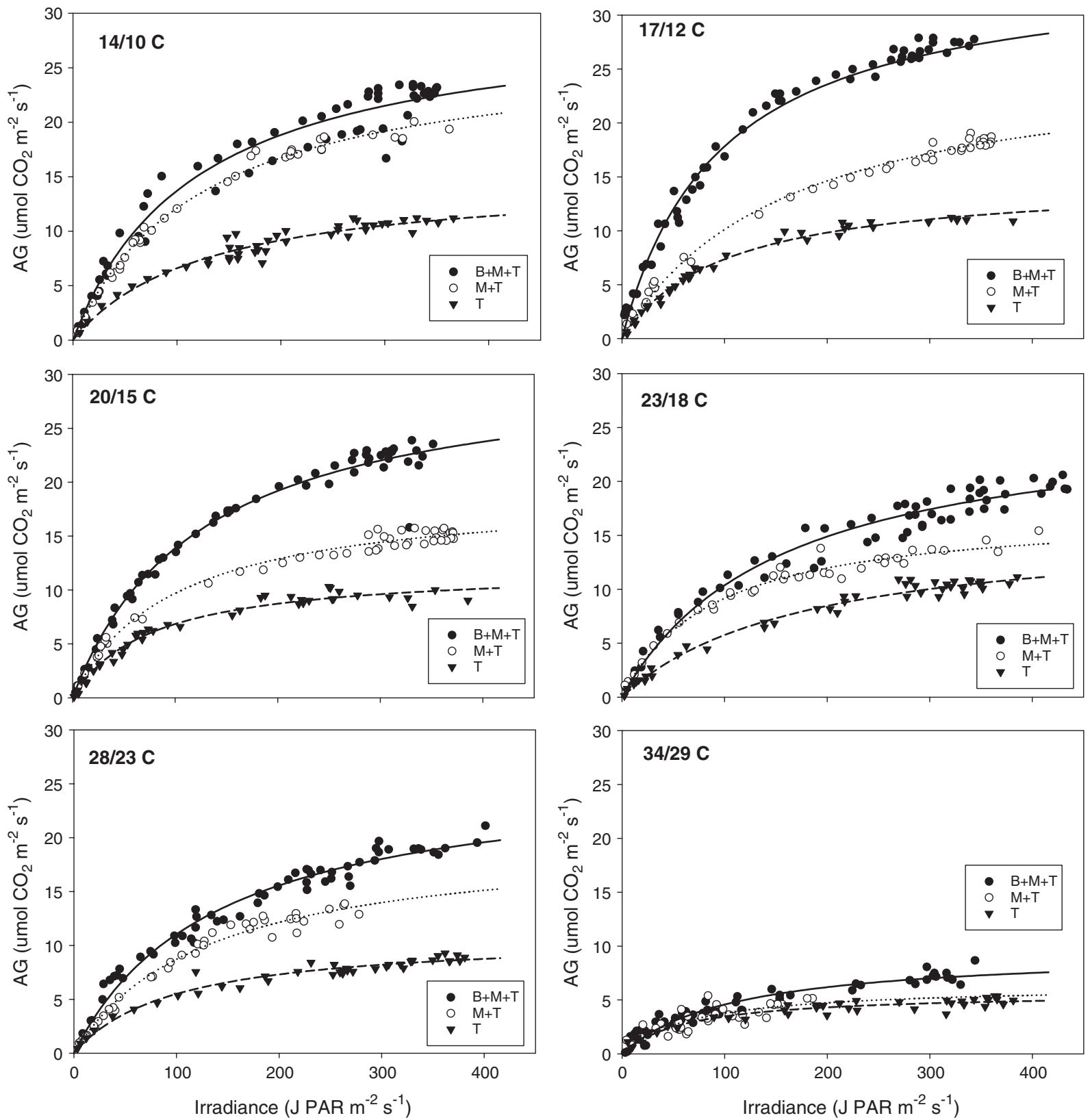

Fig. 5. Measured data (symbols) and simulated (lines) values (using Eq. [3] and parameters in Table 6) of canopy gross photosynthetic rate ( $\left.A_{G}\right)$ vs. irradiance at successive harvest dates. Alternative units: $1 \mathrm{~J}$ PAR $=4.57 \mu \mathrm{mol}$ (Thimijan and Heins, 1983).

with an initial decline from the peak seasonal values in daily photosynthetic rates for the temperature treatments (data not shown). Thus, measured harvest components obtained describe the canopy composition at or close to maximum leaf area index.

\section{Harvest Components}

Harvest results (Table 2, Fig. 2) confirm the strong influence of temperature on potato growth and development. The higher leaf areas and total and tuber dry mass, and lower stem mass measured at the cooler temperatures (Fig. 2) are consistent with Borah and Milthorpe (1962), Ewing (1997), Marinus and Bodlaender (1975), Struik et al., 1989, and Wheeler et al. (1986). The reduc- tion in tuber yield and leaf area at warmer temperatures confirms that high temperature adversely affects growth rate and tuber filling as reported by Marinus and Bodlaender (1975) and Wheeler et al. (1986).

The results indicate how main-, apical-, and basal-stem contributions to canopy development vary with temperature. Main-stem leaf areas comprised the highest fraction of total leaf area at $\sim 22^{\circ} \mathrm{C}$, while basal- and apicalstem leaf areas became more significant at warmer temperatures (Fig. 2F). Similar relations were observed for the fraction of branch dry mass in the canopy (Fig. 2E). Cool temperatures delay leaf physiological aging and senescence (Firman et al., 1995; Ng and Loomis, 1984), increase individual leaf expansion and area (Kirk and Marshall, 1992), and decrease total leaf number and stem 
branching in potato (Marinus and Bodlaender, 1975). Borah and Milthorpe (1962) suggested the increased number of leaf and stem organs at higher temperatures creates more competition for assimilate supply, the result being less canopy leaf area and smaller tuber yield compared with cooler temperatures. The implication from these results is that, at cooler temperatures, less canopy structure is needed to maximize light interception and tuber production.

These observations were further supported by classification of leaf area by stem type at different canopy layers (Table 4). Main-stem leaves accounted for $>40 \%$ of the leaf area within each canopy layer at $23^{\circ} \mathrm{C}$ and below (Fig. 4). In the potato plant, main-stem leaves form before the formation of apical-stem leaves. Thus, the large contribution of main-stem leaf area from the bottom and middle layers supports the observation that cool temperatures increase chronological leaf duration (Firman et al., 1995; Ng and Loomis, 1984). The larger main-stem leaf areas at these colder temperatures may also have suppressed formation of basal-stem branches by increasing the amount of shade in the lower canopy (Vos, 1995).

\section{Photosynthetic Parameters}

Light use efficiency and $A_{\mathrm{MAX}}$ values for the full canopy $(\mathrm{B}+\mathrm{M}+\mathrm{T})$ were higher at the $20 / 15,17 / 12$, and $14 / 10^{\circ} \mathrm{C}$ treatments than the $23 / 18,28 / 23$, or $34 / 29^{\circ} \mathrm{C}$ treatments (Table 6). Dark respiration was higher at $28 /$ 23 and $34 / 29^{\circ} \mathrm{C}$, probably due to the higher temperatures (McCree, 1988). Because the parameters were expressed on a production-area basis, parameter differences between temperature treatments also relates to the amount of leaf area in each growth chamber at the time of harvest (Fig. 3). Parameters were statistically similar, however, at different temperature treatments when expressed on a per-unit-leaf-area basis, although $R_{\mathrm{D}}$ values for the $28 /$ 23 and $34 / 29^{\circ} \mathrm{C}$ treatments were two to three times the values at cooler temperatures (data not shown). Thus, differences in full-canopy gross photosynthetic performance at high irradiance can primarily be attributed to differences in the total amount of leaf area in the growth chamber at the time of measurement; however, canopy net photosynthetic performance, and thus plant growth rate, is strongly affected by temperature in terms of its effects on respiration.

The decline in $\alpha$ and $A_{\mathrm{MAX}}$ as successive layers were removed from the canopy (Table 6) was probably due to the decrease in light interception as leaf area was removed. These results were consistent with canopy photosynthetic responses reported in a similar study with tomato (Lycopersicon esculentum Mill., Acock et al., 1978), where canopy net photosynthetic rate, expressed on a production-area basis, was strongly affected when the leaf area index was reduced to a value of 3.0 and lower. The decline in $\alpha$ with successive layers of leaf removal indicates a decrease in photosynthetic rate at lower, nonsaturating levels of irradiance. This result indicates that lower canopy leaves, although physiologically older, still contribute toward light use efficiency of the full canopy
(Table 6). The largest decreases in $A_{\text {MAX }}$ occurred following removal of the middle canopy layer, which contained significantly more leaf area than the bottom layer. The $20 / 15$ and $23 / 18^{\circ} \mathrm{C}$ treatments showed a larger decrease in $A_{\text {MAX }}$ following removal of the bottom layer; however, only limited gas exchange data was obtained on that harvest date at high irradiance due to partly cloudy skies (Fig. 5). The $A_{\mathrm{MAX}}$ value in the top canopy layer accounts for $>50 \%$ of the full canopy value and \% IPAR, confirming the fact that canopy photosynthetic rate and light interception is primarily dependent on the uppermost canopy leaves, regardless of the composition of the canopy within this layer.

\section{Implications for Modeling}

The data provide unique information on potato canopy growth and development under controlled conditions. The data can be used to test leaf area predictions across a wide range of temperatures from potato models such as SIMPOTATO (Hodges, 1992) or SUBSTOR (IBSNAT, 1993) that depict canopy growth as a single large stem and homogenous leaf layer. More sophisticated modeling approaches that estimate canopy photosynthetic rate by integrating gas exchange from different leaf layers in the plant canopy have also been developed (Boote and Pickering, 1994; Ng and Loomis, 1984). The data on leaf appearance and expansion on lateral branches at different depths in the canopy can be used to test the canopy growth component of these models (Fleisher et al., 2006). In particular, the model simulations of lateral-stem growth can be evaluated. As the results indicate, the contribution of lateral-stem leaf area to canopy development at warmer temperatures is an important response in potato.

The gas exchange data (Table 6, Fig. 5) indicate that accurate estimates of leaf area (and light interception) are critical to obtain reasonable predictions of instantaneous gross photosynthetic rates. The distribution of leaf area within a particular canopy layer according to different stem types was not as important as the quantity of leaf area. The primary influence of temperature appeared to be on the production of canopy leaf area and dark respiration rates (Table 6). Thus, models that are intended to be used solely for yield prediction should be focused on improving estimates of leaf area and light interception and do not necessarily need to simulate apical and basal stems to the level of detail obtained in this study. While the data cannot be used to develop modeling routines for gas exchange, it can be used to test model predictions of photosynthesis at corresponding leaf areas and temperatures.

Potato models for use in scientific investigations, however, such as global warming scenarios and identification of desirable breeding characteristics, can benefit by using the data to improve simulations of canopy growth. Our results indicate that apical- and basal-stem development and their contribution to canopy leaf area is important to understanding potato responses at high temperature. Models that are developed to include this level of detail can be used to more accurately simulate 
and evaluate potential changes in potato production in response to varying climactic conditions.

\section{CONCLUSION}

Data on potato branch and leaf area distribution in mature canopies and their contribution to the wholeplant gross photosynthetic rate was obtained from SPAR chambers maintained at 16-h day/night thermoperiods of $14 / 10,17 / 12,20 / 15,23 / 18,28 / 23$, and $34 / 29^{\circ} \mathrm{C}$. Canopies were divided into three horizontal layers of equal depth and defoliated at each layer, from the ground upward, on successive days. Regression analysis of harvest data vs. temperature indicated growth patterns consistent with the literature; total and tuber dry mass and canopy leaf area decreased with increasing temperatures while stem dry mass increased. Novel data were obtained on the distribution of leaf area within the canopy according to different branch types (main, apical, and basal stems). Specifically, main-stem leaf area was the largest fraction of the leaf area of all three canopy layers at daily air temperatures $23^{\circ} \mathrm{C}$ and below. As temperature increased, apical- and basal-stem leaf area comprised the largest component of the leaf area in each canopy layer. These results indicate that lateral branch development in potato plays the largest role in canopy growth and developmental response to increasing temperatures.

Gas exchange measurements vs. irradiance were obtained following successive removal of each canopy layer. Before harvest of the first canopy layer, canopy maximum gross photosynthetic rates, $A_{\mathrm{MAX}}$, ranged from 9.5 to $34.8 \mu \mathrm{mol} \mathrm{CO} \mathrm{CO}_{2} \mathrm{~m}^{-2} \mathrm{~s}^{-1}$ (production-area basis) and were higher at $14 / 10,17 / 12$, and $20 / 15^{\circ} \mathrm{C}$ temperature regimes than at $23 / 18,28 / 23$, and $34 / 29^{\circ} \mathrm{C}$. These differences were largely related to the quantity of leaf area within each chamber and canopy layer as opposed to an influence of temperature or stem type on photosynthetic performance. The values of $A_{\mathrm{MAX}}$ and canopy light use efficiency declined as successive canopy layers were removed, primarily due to decreases in light interception in the canopy.

These results indicate that potato models intended for use in yield predictions should be focused on improving estimates of leaf area and light interception and do not necessarily need to simulate apical and basal stems to the level of detail obtained in this study. Models intended for scientific investigation, however, such as global climate change impact and identification of potato branching characteristics important for breeding trials, can benefit by using the data to provide an additional level of detail in canopy growth and development. The results indicate that apical- and basal-stem development and their contribution to canopy leaf area is important to understanding potato responses at high temperature. Models that are developed to include this level of detail can be used to more accurately simulate and evaluate potential changes in potato production in response to varying climatic conditions. The data set can support both model development and validation of these goals.

\section{REFERENCES}

Acock, B., D.A. Charles-Edwards, D.J. Fitter, D.W. Hand, L.J. Ludwig, J.W. Wilson, and A.C. Withers. 1978. The contribution of leaves from different levels within a tomato crop to canopy net photosynthesis: An experimental examination of two canopy models. J. Exp. Bot. 29:815-827.

Allen, E.J., and R.K. Scott. 1980. An analysis of growth of the potato crop. J. Agric. Sci. 94:583-606.

Baker, J.T., S.-H. Kim, D.C. Gitz, D. Timlin, and V.R. Reddy. 2004. A method for estimating carbon dioxide leakage rates in controlledenvironment chambers using nitrous oxide. Environ. Exp. Bot. 51: 103-110.

Benoit, G.R., W.J. Grant, and O.J. Devine. 1986. Potato top growth as influenced by day-night temperature differences. Agron. J. 78:264-269.

Boote, K.J., and N.B. Pickering. 1994. Modeling photosynthesis of row crop canopies. HortScience 29:1423-1434.

Borah, M.N., and F.L. Milthorpe. 1962. Growth of the potato as influenced by temperature. Ind. J. Plant Physiol. 5:53-72.

Dutton, R.G., J. Jiao, M.J. Tsujita, and B. Grodsinski. 1988. Whole plant $\mathrm{CO}_{2}$ exchange measurements for nondestructive estimation of growth. Plant Physiol. 86:355-358.

Ewing, E.E. 1997. Potato. p. 295-343. In H.C. Wien (ed.) The physiology of vegetable crops. CABI Int., Cambridge, MA.

Firman, D.M., P.J. O’Brien, and E.J. Allen. 1995. Appearance and growth of individual leaves in the canopies of several potato cultivars. J. Agric. Sci. 125:379-394.

Fleisher, D.H., R.M. Shillito, D.J. Timlin, S.-H. Kim, and V.R. Reddy. 2006. Approaches to modeling potato leaf appearance rate. Agron. J. 98:522-528.

Hammes, P.S., and J.A. De Jager. 1990. Net photosynthetic rate of potato at high temperatures. Potato Res. 33:515-520.

Hodges, T. 1992. A modular structure for crop simulation models: Implemented in the SIMPOTATO model. Agron. J. 84:911-915.

IBSNAT. 1993. A simulation model for potato growth and development: SUBSTOR-Potato Version 2.0. Res. Rep. Ser. 02. Dep. of Agron. and Soil Sci., College of Tropical Agric. and Human Resour., Univ. of Hawaii, Honolulu.

Kirk, W.W., and B. Marshall. 1992. The influence of temperature on leaf development and growth in potatoes in controlled environments. Ann. Appl. Biol. 120:511-525.

Kooman, P.L., and A.J. Haverkort. 1995. Modelling development and growth of the potato crop influenced by temperature and daylength: LINTUL-POTATO. p. 41-60. In A.J. Haverkort and D.K.L. MacKerron (ed.) Potato ecology and modeling of crops under conditions limiting growth. Kluwer Acad. Publ., Boston.

Ku, S.B., G.E. Edwards, and C.B. Tanner. 1977. Effects of light, carbon dioxide, and temperature on photosynthesis, oxygen inhibition of photosynthesis, and transpiration in Solanum tuberosum. Plant Physiol. 59:868-872.

Littell, R.C., G.A. Milliken, W.W. Stroup, and R.D. Wolfinger. 1996. SAS system for mixed models. SAS Inst., Cary, NC.

Loomis, R.S., and D.J. Connor. 1996. Photosynthesis. p. 257-288. In R.S. Loomis and D.J. Connor (ed.) Crop ecology: Productivity and management in agricultural systems. Cambridge Univ. Press, New York.

Manrique, L.A., D.P. Bartholomew, and E.E. Ewing. 1989. Growth and yield performance of several potato clones grown at three elevations in Hawaii: I. Plant morphology. Crop Sci. 29:363-370.

Marinus, J., and K.B.A. Bodlaender. 1975. Response of some potato varieties to temperature. Potato Res. 18:189-204.

McCree, K.J. 1988. Sensitivity of sorghum grain yield to ontogenetic changes in respiration coefficients. Crop Sci. 28:114-120.

Ng, N., and R.S. Loomis. 1984. Simulation of growth and yield of the potato crop. Simulation Monogr. Ser. Pudoc, Wageningen, the Netherlands.

Prange, R.K., K.B. McRae, D.J. Midmore, and R. Deng. 1990. Reduction in potato growth at high temperature: Role of photosynthesis and dark respiration. Am. Potato J. 67:357-369.

Reddy, K.R., J.T. Baker, V.R. Reddy, J. McKinion, L. Tarpley, and J.J. Read. 2001. Soil Plant-Atmosphere-Research (SPAR) facility: A tool for plant research and modeling. Biotronics 30:27-50.

Reddy, V.R., B. Acock, and M.C. Acock. 1989. Seasonal carbon and nitrogen accumulation in relation to net carbon dioxide exchange in a carbon dioxide enriched soybean canopy. Agron. J. 81:78-83. 
Robinson, J.M. 1984. Photosynthetic carbon metabolism in leaves and isolated chloroplasts from spinach plants grown under short and intermediate photosynthetic periods. Plant Physiol. 75:397-409.

SAS Institute. 2001. The SAS system for Windows. Version 8.02. SAS Inst., Cary, NC.

Shaykewich, C.F., G.H.B. Ash, R.L. Raddatz, and D.J. Tomasiewicz. 1998. Field evaluation of a water use model for potatoes. Can. J. Soil Sci. 78:441-448.

Steward, F.C., U. Moreno, and W.M. Roca. 1981. Growth, form and composition of potato plants as affected by environment. Ann. Bot. 48:1-45.

Struik, P.C., J. Geertsema, and C.H.M.G. Custers. 1989. Effects of shoot, root and stolon temperature on the development of the potato (Solanum tuberosum L.) plant: I. Development of the haulm. Potato Res. 32:133-141.

Thimijan, R.W., and R.D. Heins. 1983. Photometric, radiometric, and quantum light units of measure: A review of procedures for interconversion. HortScience 18:818-822.

Thornton, M.K., N.J. Malik, and R.B. Dwelle. 1996. Relationship between leaf gas exchange characteristics and productivity of potato clones grown at different temperatures. Am. Potato J. 73:63-77. van Delden, A., M.J. Kropff, and A.J. Haverkort. 2001. Modeling temperature- and radiation-driven leaf area expansion in the contrasting crops potato and wheat. Field Crops Res. 72:119-142.

van Iersel, M.W., and J.G. Kang. 2002. Nutrient solution concentration affects whole-plant $\mathrm{CO}_{2}$ exchange and growth of subirrigated pansy. J. Am. Soc. Hortic. Sci. 127:423-429.

Vos, J. 1995. Foliar development of the potato plant and modulations by environmental factors. p. 21-38. In P. Kabat et al. (ed.) Modeling and parameterization of the soil-plant-atmosphere system: A comparison of potato growth models. Wageningen Pers, Wageningen, the Netherlands.

Vos, J., and H. Biemond. 1992. Effects of nitrogen on the development and growth of the potato plant: I. Leaf appearance, expansion growth, life spans of leaves and stem branching. Ann. Bot. 70: 27-35.

Wheeler, R.M., K.L. Steffen, T.W. Tibbitts, and J.P. Palta. 1986. Utilization of potatoes for life support systems: II. The effects of temperature under 24-h and 12-h photoperiods. Am. Potato J. 63:639-647.

Wolf, S., A. Marani, and J. Rudich. 1990. Effects of temperature and photoperiod on assimilate partitioning in potato plants. Ann. Bot. 66:513-520. 